\title{
Experiências de turismo em unidades de conservação em áreas haliêuticas no Estado do Pará/Amazônia
}

\author{
Helena Doris de Almeida Barbosa* \\ Universidade Federal do Pará (Brasil)
}

\author{
Raul Ivan Raiol de Campos** \\ Universidade Federal do Pará (Brasil)
}

\begin{abstract}
Resumo: O Turismo enquanto atividade multidimensional tem nos recursos biossociais sua principal matéria-prima, que na Amazônia se concentram nas Unidades de Conservação (UC), principalmente em áreas litorâneas, com ricos ecossistemas de cenários paradisíacos e de aventuras demandados pelo turismo. AAmazônia Oriental1, ocupada desde a pré-história por populações especializadas na obtenção dos recursos aquáticos para sua reprodução vem sofrendo transformações, dentre elas, a criação de UC e o turismo. Como isso vem ocorrendo é o que se debate, discutindo como as comunidades pesqueiras do nordeste paraense participaram ou não na criação das UC, e como o turismo nelas efetivado se configura. A relevância desta discussão justifica-se pelo fato da diversidade social presente na Amazônia, ser ignorada pelo Estado, tanto na criação de políticas ambientais, como no fomento de ações alternativas de desenvolvimento para as mesmas, como o turismo.
\end{abstract}

Palavras-Chave: Turismo; Unidades de Conservação; Comunidades Pesqueiras; Amazônia Oriental.

Tourism Experiences in Conservation Units in Fisheries in the State of Pará / Amazônia

Abstract: Tourism as a multidimensional activity has in the biosocial resources its main product, which in the Amazon is concentrated in Protected Areas, especially those located on coastal areas, with their rich ecosystems of beautiful landscape and of adventures demanded by tourism. The East Amazon, which was inhabited in the pre-history by population specialized in getting aquatic resources for their reproduction, is now going through transformations, among them, creation of Protected Areas and tourism. How these transformations are going on is debated, discussing how local communities of Northeast of Pará State participate or not in the creation of Protected Areas and how tourism is managed and designed. The relevance of this discussion is due to the fact that social diversity in the Amazon be ignored by State, not only in the creation of environmental politics, but also in providing alternatives of development for these communities, such as tourism.

KeyWords: Tourism; Protected Areas, Fishermen Communities; East Amazon.

\section{Introdução}

As sociedades haliêuticas têm se deparado ao longo de sua história com dinâmicas naturais, sociais, simbólicas, econômicas e políticas, por meio de interações intensas e em larga escala que por séculos se (re)constroem. Entretanto, a partir dos séculos XVIII e XIX, o mercantilismo, o avanço tecnológico e a internacionalização econômica imputaram uma nova ordem global, um novo paradigma de desenvolvimento que emerge e se dinamiza com a crença de que a humanidade atravessa uma crise sem precedentes. Alternativas das mais diversas ordens vêm sendo debatidas

\footnotetext{
Doutora em Desenvolvimento Sócio-Ambiental pelo Programa de Pós-Graduação em Desenvolvimento Sustentável do Trópico Úmido do NAEA/UFPA; E-mail: hdoris@ufpa.br

** Doutorado em Desenvolvimento Sustentável do Trópico Úmido pela Universidade Federal do Pará/Núcleo de Altos Estudos Amazônicos; E-mail: raulcampos@ufpa.br]
} 
e apontadas no sentido de tentar reverter este processo, dentre elas a criação de áreas protegidas, mais especificamente das UC que se apresentam como uma das muitas estratégias, além da inserção do turismo, como alternativa de desenvolvimento local em sociedades haliêuticas, haja vista a disponibilidade de recursos naturais e culturais ideais à práxis turística.

O processo de criação de UC se efetivou de maneira impositiva e centralizadora, a partir de modelos exógenos, não levando em consideração as especificidades sociais locais. O turismo, por sua vez, vem sendo apontado como uma alternativa econômica com perspectivas de sustentabilidade e um meio para conservação dos recursos naturais e culturais. Desse modo, a Amazônia passa a ser o alvo mais demandado para o fluxo no segmento do "ecoturismo" inserindo-se, assim, nos roteiros turísticos nacionais e internacionais direcionados para a sustentabilidade socioambiental. Até que ponto isso, de fato, vem ocorrendo nas UC que abrangem sociedades pesqueiras, é o que se pretende relativizar.

Neste trabalho objetiva-se compreender as questões que fundamentam a problemática do turismo em áreas protegidas no litoral do Pará, ainda mais quando estas se localizam em áreas pesqueiras, onde se acredita que tal atividade pode contribuir sobremaneira para a consolidação ou não das UC. O Turismo em interface com as sociedades haliêuticas pode se constituir em uma prática sustentável, assim como, promotora de um desenvolvimento coletivo e integrado. Além disso, pretende-se discutir de que maneira estas sociedades vem sendo envolvidas ou não nas criações de UC, se estas contemplam o turismo em seus Planos de Manejo e até que ponto o turismo efetivado nas mesmas circunscreve-se na perspectiva da inserção social.

Este trabalho foi produzido a partir da aglutinação de procedimentos metodológico-conceituais em uma perspectiva interdisciplinar, haja vista os diversos aspectos envolvidos na temática abordada, tais como processos ecológicos, sócio-espaciais, culturais e políticos. Nesse sentido, a congregação de enfoques relacionados à Antropologia, Sociologia e ao Turismo permitiu identificar os possíveis conflitos e tensões presentes na prática da atividade turística em UC em áreas de populações pesqueiras no litoral paraense, bem como o estabelecimento das correlações existentes entre os vários setores envolvidos no processo, os papéis, expectativas e atuações que compõem o cenário em questão. Tomando como objeto os trabalhos e as pesquisas desenvolvidas na APA de Algodoal/Maiandeua, na RESEX Marinha de Maracanã, na RESEX Marinha Mãe Grande de Curuçá e na RESEX Caeté-Taperaçu, pretende-se evidenciar as questões acima expostas permitindo a construção de um cenário aproximado sobre a realidade do turismo em UC em áreas haliêuticas no Pará.

A relevância desta discussão se justifica pelo fato de a diversidade social ser um fator importante na Amazônia, no entanto esta vem sendo sempre ignorada pelo Estado, seja no que tange a criação de políticas ambientais, seja no fomento de ações/linhas de crédito que venham a dinamizar alternativas viáveis de desenvolvimento para as sociedades pesqueiras, neste caso, o turismo. Apesar de as questões da conservação, da biodiversidade e do desenvolvimento se converter em presenças efetivas nos mais diversos fóruns e discussões acerca dos problemas ambientais, a efetividade prática das ações políticas podem ser questionadas, seja pelo desconhecimento das especificidades sociais da região, seja pelo distanciamento dos estudos elaborados nestes espaços, que poderiam apontar viabilidades para a minimização dos conflitos existentes nestas áreas.

Nesse contexto, faz-se necessário, apesar desse "novo" momento e das disposições normativas existentes, contribuir para que se impulsione o desenvolvimento sustentável na Amazônia, reconhecendo a importância da construção de um Estado social de direito que faça alcançar um desenvolvimento que seja prudente, equiparando suas relações econômicas, sociais, ambientais e culturais, inserindo-se ainda as questões históricas.

\section{As Interfaces do Turismo e as Unidades de Conservação}

O setor turístico no século XXI de acordo com Naisbitt (1994) alcançará patamares expressivos, transformando-se em uma das principais fontes de captação de recursos. No âmbito deste processo de expansão e diversificação da atividade em atender as demandas emergentes do mercado turístico, muitas vezes, o turismo se direciona para áreas naturais que fazem parte de áreas protegidas, mas sem uma articulação de sua prática com as diretrizes que norteiam as atividades antrópicas em UC. 
Diversos autores vêm trabalhando com a questão da expansão do turismo na sociedade contemporânea. Stronza (2001: 261) adverte que

[...] the more holistic perspective will be important as we explore the ways in which ecotourism and other alternative forms of tourism can generate social, economic and environmental benefits for local communities while also creating truly transformative experiences for tourists.

Para Ruschman (1997), sua prática enquanto atividade multidimensional utiliza-se dos recursos naturais como fonte de recuperação do equilíbrio psicofísico. Krippendorf (1989), Lemos (1996) e Rodrigues (1996) analisam o surgimento do turismo enquanto atividade emergente da sociedade contemporânea. Essa seria motivada por interesses de dominação por parte dos países do primeiro mundo sobre os subdesenvolvidos, enquanto detentores de riquíssimos recursos naturais de interesse turístico. Frente a isso, são desencadeados processos de transformações sociais, econômicas, espaciais e ambientais pautados pelas demandas do mercado. A postura da sociedade diante deste quadro e a busca da diversificação do produto oferecido, fez surgir o segmento do ecoturismo, tendo como base o paradigma do turismo sustentável, que vem sendo analisado por Ruschman (1997), Swarbrooke (2000), Seabra (2001) e Castro (2002).

O efeito multiplicador do turismo abrange direta e indiretamente vários atores sociais. Em virtude desta amplitude, o aspecto que mais se destaca é o econômico, haja vista que quando se fala em turismo, pensa-se logicamente nos lucros e divisas que ele pode gerar, principalmente por ser uma das atividades que mais cresce no mundo. Entretanto, o desenvolvimento do turismo voltado exclusivamente para seu viés econômico desencadeou o processo de massificação da atividade, convencionalmente chamado de turismo de massa2. Este tipo de turismo tem transformado regiões, descaracterizado culturas, dentre elas as comunidades haliêuticas, impondo-se sem nenhum compromisso local, inclusive, causando impactos mais negativos do que positivos para o meio ambiente e para os residentes locais (Seabra, 2001; Simonian, 2003). Tal contexto é resultado da ausência de uma "cultura turística", que no dizer de Ruschman (1997: 23) faz com que os turistas se comportem de modo alienado em relação ao meio onde visitam, que Yázigi (1999) denomina de "vandalismo paisagístico3".

Assim, surgiram novas alternativas de turismo que consideram não somente os aspectos econômicos, mas também os aspectos sociais, culturais e ambientais. Então, o viés da sustentabilidade passa a ser o elemento ideal do turismo contemporâneo, tendo como perspectiva teórica e prática o turismo sustentável, que pode ser definido como:

Aquele que é desenvolvido e mantido em uma área (comunidade, ambiente) de maneira que, e em uma escala que, se mantenha viável pelo maior tempo possível, não degradando ou alterando o meio ambiente que usufrui (natural e cultural), não interferindo no desenvolvimento de outras atividades e processo, não degradando a qualidade de vida da população envolvida, mas pelo contrário servindo de base para uma diversificação da economia local (Wall, 1997 apud Kinker, 2002:17).

Ou aquele que é “ [...] economicamente viável, mas não destrói os recursos dos quais o turismo no futuro dependerá, principalmente o meio ambiente físico e o tecido social da comunidade local" (Swarbrooke, 2000:19). Para Seabra (2001) consiste em uma maneira de lazer harmoniosa, fundamentada na autodeterminação, na valorização das populações nativas e no respeito ao meio ambiente. Uma definição mais completa e holística é a de que a atividade se constitui em um

Descritor amplo para todos os tipos de turismo, baseado em recursos naturais ou produzidos pelo homem, centrado na noção de temporalidade, envolvendo gerações presentes e futuras, no compromisso de conservação ambiental e valorização de patrimônio cultural, e no engajamento das comunidades locais no processo de tomada de decisões, no sentido de construção de capital social (Irving; Rodrigues; Neves Filho, 2002:95) 
Então, de acordo com Ignarra (1999), o turismo sustentável ganhou força no meio acadêmico, e parece ser a perspectiva mais viável para a atividade por ser ecocêntrica e inclusiva, não só porque engloba todos os tipos de turismo, mas também porque considera todos os sistemas envolvidos no seu desenvolvimento. Nesse contexto, a Amazônia passa a ser o alvo mais demandado para o fluxo do ecoturismo, inserindo-se assim nos roteiros turísticos nacionais e internacionais direcionados para a sustentabilidade ecológica4 Desse modo, as UC surgem como pontos centrais para o desenvolvimento do turismo e para a possibilidade de inclusão das sociedades amazônicas neste processo.

A Amazônia é detentora de diversas categorias de UC que, segundo Veríssimo et al (2011) perfazem um total de 308 (trezentos e oito) UC, que correspondem a 23,5\% da Amazônia Legal, que vem, ao longo do tempo, se tornando foco de interesse à prática da atividade turística. O estado do Pará, por sua vez, tem 49 UC (federais e estaduais), que perfazem cerca de 38 milhões de hectares (World Wildlife Fund-Brasil, 2011), destas, parte significativa localizada em áreas já utilizadas pelo turismo de maneira formal ou não em função da disponibilidade de seus atrativos e possibilidades de uso para recreação e lazer.

Trabalhos que analisam a trajetória da criação das UC e suas problemáticas, já vêm sendo produzidos por Diegues (1994), Irving (2002), Simonian (1998), Pinto e Campos (1994), Quaresma (2003), dentre outros evidenciando a complexidade e assimetria de ações na gestão destes espaços e de seus usos, bem como o modelo alienador que moldou o processo de constituição da criação de UC desde 1937, por ocasião da criação do Parque Nacional de Itatiaia no Rio de Janeiro. Mas, a gênese da criação de UC no Brasil foi pautada pelo modelo preservacionista de áreas naturais - "modelo yellowstone" - no qual a presença humana não era permitida (Diegues, 1994).

$\mathrm{O}$ avanço da política ambiental brasileira consolidou um aparato legal que integra as UC brasileiras, normatizando suas criações e usos através do Sistema Nacional de Unidades de Conservação (SNUC), regulamentado pela Lei $\mathrm{n}^{\circ} 9.985$ de 2000. De acordo com o SNUC, as UC "são espaços territoriais e seus recursos ambientais, incluindo as águas jurisdicionais, com características naturais relevantes, legalmente instituídos pelo Poder Público, com objetivos de conservação e limites definidos, sob regime especial de administração, ao qual se aplicam garantias adequadas de proteção" (Brasil, 2000:1).

As UC dividem-se em duas categorias: Uso Indireto, destinadas à conservação da biodiversidade, à pesquisa científica, à educação ambiental e à recreação, compreendendo as Estações Ecológicas, Reservas Biológicas, Parques Nacionais/Estaduais, Monumento Natural, e Refugio da Vida Silvestre. Estas estão totalmente vedadas à exploração dos recursos naturais, admitindo apenas o aproveitamento indireto de seus recursos. E as UC de Uso Direto que são destinadas à conservação da biodiversidade, onde se permite utilizar os recursos de modo sustentável, estabelecendo modelos de desenvolvimento. Compõe esta categoria as Florestas Nacionais, as Áreas de Proteção Ambiental, Área de Relevante Interesse Ecológico, Reserva de Fauna, Reserva de Desenvolvimento Sustentável, Reserva Particular de Patrimônio Natural e as Reservas Extrativistas.

Hoje a instância máxima de gestão destas unidades está a cargo do Instituto Chico Mendes da Biodiversidade (ICMBIO), e apesar de o considerável número de UC na região amazônica decretadas pelas esferas federal, estadual, municipal e algumas particulares, tais ações ainda deixam muito a desejar, uma vez que a efetividade de criação, implementação e gestão se dá de maneira fragmentada, passando essas iniciativas a ser, muitas vezes, alvo de críticas por parte de vários setores da sociedade. Veríssimo et al (2011:31) ratificam tal perspectiva ao afirmar que:

Apesar da elaboração do plano de manejo ser obrigatória em um prazo máximo de cinco anos após o decreto de criação da Unidade, a maioria (70\%) dos planos das Unidades de Conservação da Amazônia Legal ainda não foi iniciada ou não está concluída. Das 308 UCs estaduais e federais analisadas, apenas $24 \%$ possuíam planos de manejo aprovados; $1 \%$ estava com seus planos em fase de revisão; $20 \%$ estava na fase de elaboração, e 50\% sequer tinham iniciado seus planos de manejo em dezembro de 2010.

Tal situação tem sua gênese, segundo Moreira e Anderson (1996), nas inúmeras visões divergentes sobre o papel das áreas naturais protegidas associada à questão da presença humana nessas áreas. Desde 1992, de acordo com os mesmos autores, os debates em torno de UC se efetivam no 
sentido de construir um consenso no que tange as propostas legislativas do SNUC no Brasil, e mais recentemente os debates giram em torno dos aspectos conceituais das categorias de áreas protegidas (Pereira; Scardua, 2008).

Enquanto esse processo se dá, Seabra (2001:42) alerta para o fato de que "nos últimos anos, a perda da tutela da União sobre os espaços protegidos é facilitada pelo estabelecimento de convênios, parcerias e cogestão entre o poder público, o setor particular e as organizações não-governamentais". Como alternativa de reversão Fennel (2002:85) propõe a partir de Dearden (1991) que "as filosofias de gestão dos parques tornem-se mais integradas, reconhecendo que estes parques não existem como ilhas ecológicas, mas precisam ser gerenciados de acordo com as condições ambientais, tanto dentro quanto fora de suas fronteiras", ou seja, seu entorno.

Outro ponto que se apresenta como comprometedor do êxito das UC é a não conclusão/implementação dos planos de manejo destas áreas, que zonificam os espaços a serem utilizados (Quaresma, 2000), quando não, o tempo muito longo de elaboração destes planos. Estes se constituem, também, em nos mais importantes fatores de críticas e controvérsias que giram em torno do Estado, sua ação na gestão e monitoramento das UC. Logo, fica comprometido o cumprimento das finalidades destas áreas que, na maioria das vezes, não têm concluído e implantados seus planos de manejo, associado ao fato do desconhecimento e alienação da população local no processo de criação/implementação destas unidades.

Uma das estratégias, por parte do Estado, para o uso público das UC para a Amazônia se dá através do Programa de Desenvolvimento do Turismo Sustentável (PRODETUR). No caso do estado do Pará, a implantação do PRODETUR/PARÁ demandou US\$ 44 milhões de dólares, sendo que US $\$ 26,4$ milhões do BID e US\$17,6 milhões do governo do estado do Pará (Nascimento, 2009). Atualmente, o PRODETUR/PARÁ está com a proposta de desenvolvimento de operação concluída, faltando somente a fase de aprovação e contração da operação do mesmo, tendo com área de área de abrangência os pólos Belém, Marajó e Tapajós.

O turismo vem sendo apontado com uma alternativa econômica com perspectiva de sustentabilidade e alternativa para conservação dos recursos naturais e culturais em UC. Exemplo disso cita-se o estudo realizado por Medeiros e Young (2011), que analisa o impacto econômico do uso público (visitação) nas UC brasileiras. Os autores utilizaram a metodologia "Money Generation Model" desenvolvido pela Universidade de Michigan e pelo National Park Service para avaliar o impacto econômico da visitação nas UC brasileiras. Dentre os resultados, destacam-se as estimativas de 2009 que os autores fizeram para os Parques Nacionais da Tijuca e Iguaçu que são os mais visitados, tem infraestrutura satisfatória e controle do fluxo de visitantes, inclusive, por terem os serviços de visitação, monitoramento e gestão terceirizados. Em um cenário otimista com uma visitação de 1.689.472 e um gasto médio de $\mathrm{R} \$ 107,40$, o impacto econômico no Parque Nacional da Tijuca foi de $\mathrm{R} \$ 345.958 .011,92$; também com o mesmo cenário com visitação de 1.070 .072 e um gasto médio de $\mathrm{R} \$ 50,00$, o impacto econômico no Parque Nacional do Iguaçu foi de $\mathrm{R} \$ 85.605 .760,00$. Os autores estimaram ainda o potencial impacto econômico da visitação em 67 parques nacionais para 2016 em $\mathrm{R} \$ 1.776 .300,474,94$ para um cenário otimista. Isto reflete os esforços e amadurecimento de alguns setores sociais no sentido de coadunar a preservação dos recursos naturais com o uso racional dos mesmos. Neste sentido, Castro (2002:134) ressalta "que as ONGs têm desempenhado função importante pelas pressões em favor do turismo sustentável".

Estudos no sentido de analisar de que maneira o turismo vem se implantando em UC já foram realizados em outras categorias de áreas protegidas no Brasil. Entre eles, Costa e Costa (2000) estudaram o turismo no Parque Estadual da Pedra Branca RJ, Costa (2002) estudou o Parque Estadual Paulo Cezar Vinha (ES) e Reserva Natural Salto Morato (PR); Sansolo (2002) estudou a Reserva Biológica de Osório (RS) e o Parque Estadual da Serra do Mar (SP); Irving, Rodrigues e Neves Filho (2002) analisaram tal temática no Parque Estadual do Desengano (RJ). Em Parques Nacionais brasileiros podem ser citados os trabalhos de Niefer, Silva e Amend (2000), nos quais fizeram um perfil dos visitantes do PARNA de Superagui (PR), e Kinker (2002), que trabalhou com o PARNA de Aparados da Serra (RS/SC), PARNA da Serra Geral (RS/SC) e o Parque Nacional de Caparaó (MG/ES).

$\mathrm{Na}$ Amazônia tais estudos vêm sendo dinamizados por Quaresma $(2003,2008)$ que analisa tal atividade em duas categorias distintas de UC, a APA de Algodoal/Maindeua (PA) e no Parque 
Nacional de Monte Roraima (BR) e Parque Nacional Canaima (VE), Campos (2008) que analisa a atividade no Parque Estadual da Serra dos Martírios, Gomes (2007) que trabalhou a questão do turismo no entorno do Parque Nacional de Cabo Orange (AP), Pinto (2006) que analisa tal problemática relacionada a exclusão social das comunidades que integram o Parque Estadual da Serra dos Martírios/Andorinhas e na RESEX Marinha de Soure. Evidentemente nem todos se configuram em espaços haliêuticos, no entanto, é para essas áreas que a dinâmica da atividade vem sendo imputada.

\section{O Turismo em Áreas Haliêuticas no Pará}

O turismo é a atividade que neste século, segundo a OMT, vem apresentando um dos maiores crescimentos econômicos, constituindo-se um dos principais elementos geradores de renda e emprego. Enquanto atividade multidimensional, que tem como principais elementos dinamizadores os atrativos naturais e culturais, o turismo vem se constituindo como um "fenômeno" da sociedade contemporânea, marcado pela crescente necessidade de recuperação dos desgastes físicos e mentais do cotidiano urbano-capitalista, ou de lazer. Consequentemente, tal atividade vem sendo direcionada para áreas litorâneas, detentoras de ricos ecossistemas, vindo a atender as demandas de "cenários paradisíacos" e de "aventuras", que são veiculados pelo mercado turístico nacional e internacional.

A Amazônia, mais especificamente o estado do Pará, passou a ter nestes últimos vinte anos um incremento da atividade turística, envolvendo elementos nacionais e internacionais. No Pará, tanto as áreas de estuário quanto do litoral, mais especificamente as que integram as microrregiões do Salgado, Bragantina e Viseu, caracterizam-se por vastas e ricas áreas naturais de manguezais, rios, litoral e florestas tropical, que vem sendo ocupadas desde a pré-história, por populações de caçadores-coletores especializados na obtenção dos recursos do rio e/ou do mar. Hoje, as populações que ali vivem, exercem como principal atividade à sua reprodução social a pesca artesanal, complementando-a com o cultivo de mandioca, milho e feijão, em pequenos roçados implantados em áreas de capoeira.

No conjunto de transformações em curso nas áreas litorâneas do Pará, a que vem afetando de modo mais intenso estas comunidades é o turismo, que encontra nestas localidades o "produto" ideal para o planejamento e operacionalização de seus anseios de desenvolvimento. Assim, comunidades de pescadores como Salinópolis, Ajuruteua, Marudá e Algodoal, são exemplos de áreas litorâneas que vêm, através do processo de turistificação, transformando-se em balneários turísticos, conforme os estudos realizados por Souza (2008), Adrião (2003) e Quaresma (2003). Em áreas mais próximas de Belém pode-se citar Mosqueiro e Caratateua. Este processo tem impactado, não só, as formas tradicionais de organização econômica, social e política desses moradores, mas também suas realidades simbólicas e valorativas.

$\mathrm{Na}$ esfera econômica, pode-se citar a geração de divisas, empregos, redistribuição de renda, especulação imobiliária, pressão inflacionaria, crescimento e transformação espacial da localidade, escassez de produtos. Na esfera social, há modificação da estrutura populacional, mudanças na estrutura ocupacional da comunidade, como o abandono da pesca, introdução de novas técnicas produtivas, carência de mão-de-obra qualificada, necessidade de infraestrutura básica; necessidade de serviço público adequado. Na esfera cultural, o turismo tem um duplo poder, ao mesmo tempo em que pode possibilitar o resgate e a valorização da cultura local, pode também, ser capaz de alterá-la para padrões totalmente diferenciados dos originais. E, finalmente, na esfera ambiental pode promover a poluição e esgotamento dos recursos naturais.

Tal quadro vem se instalando nas comunidades pesqueiras/coletoras, e muitas vezes, o Estado se apresenta como um facilitador deste processo seja pela omissão, ou pelo incentivo à expansão do turismo em áreas, nem sempre preparadas para tal. Essa expansão faz da atividade uma monocultura que por sua própria característica de sazonalidade imputa situações incompatíveis com o desenvolvimento. A maneira como este vem sendo praticado, o faz constituir-se em um elemento de pressão contra as comunidades pesqueiras artesanais, em vez de uma vertente de desenvolvimento e de melhoria da qualidade de vida local. 


\section{As Experiências de Turismo em Unidades de Conservação em Áreas Haliêuticas: Práticas Sustentáveis?}

Dentre as mudanças correntes mais significativas nas últimas décadas no cenário regional, têm-se aberturas de estradas, introdução de novas tecnológicas pesqueiras, especulação e valorização imobiliária, aumento das atividades extrativas que passam a comprometer a qualidade de vida de um contingente populacional significativo (Hebete, 1985; Furtado, 1987 e 1994; Maneschy, 1993; D’incao, 1994; Simonian, 1996, 1998). Isto vem afetando sobremaneira a existência das populações que tem nos recursos naturais, sua principal fonte de reprodução social e os ecossistemas com os quais estas sociedades interagem (Lima; Pozzobon, 2005).

A criação de UC em áreas de populações pesqueiras se coloca apenas como uma particularidade a mais nesta perspectiva, os processo em torno de suas criações tem sido permeados pelo discurso de preservacionistas dos recursos naturais (Diegues, 1994). No entanto, em conformidade com as afirmações de McNeely (1984), Simonian (2000), Campos (2008) e Quaresma (2003, 2008), na prática as ações voltadas para sua implementação e ou continuidade são antes problemáticas quando não, destrutivas.

A Amazônia desde que foi ocupada pelos colonizadores europeus, tem sido foco de disputa de seu espaço pelos mais diversos grupos sociais, tendo o Estado o papel de intermediador e facilitador deste processo. Tal fato se deu através da criação de inúmeros programas para o desenvolvimento da região, e que, na maioria, não obtiveram êxito esperado e geraram consequências insatisfatórias (Becker, 1991; Almeida, 1991). Esta insatisfação se deve, em grande parte, ao fato de se ignorar a existência de um contingente populacional bastante significativo, e que tem no uso dos recursos naturais a base de sua reprodução social e simbólica.

Esta nova postura do Estado de criação de UC vem sendo praticada de maneira intensiva no estado do Pará a partir das últimas duas décadas. Porém, muitas vezes sem uma participação/ articulação prévia com as comunidades que estão nestas áreas há dezenas de anos, ficando totalmente a margem deste processo, sem participar da tomada de decisões (Simonian, 1998; Quaresma, 2000). Estes problemas, assim como os demais relativos aos recursos naturais, podem ser analisados como fruto da priorização de objetivos e metas externas ao contexto local.

Associado a isso, apresenta-se o turismo, que é direcionado para estas áreas se tornando também um vetor de transformações. Na maioria das vezes, o próprio Estado fomenta este processo sem levar em conta o fato de a atividade vir a se tornar um canal de pressão sobre o ambiente biossocial e ir de encontro aos objetivos de uma UC. Ao tomar-se como referência quatro categorias diferencias de UC no nordeste paraense - a APA de Algodoal/Maiandeua (Maracanã); a RESEX Mãe Grande Curuçá (Curuçá); RESEX de Maracanã (Maracanã) e RESEX Caeté-Taperaçu em Bragança, percebe-se, no entanto, que estas têm nas suas origens, o fato da própria ausência do Estado que não as implementa de fato (algumas sem conclusão de planos de manejo e insuficiência de recursos) ou incentiva/ facilita o desenvolvimento de outras atividades que se contrapõem com as práticas sustentáveis.

Hoje as comunidades que estão em áreas que foram transformadas em UC, ressentem-se da não participação no processo de criação e instalação das mesmas, muitas delas nem sequer sabem o que seja tal unidade. Devido a postura, muitas vezes, intransigente e autoritária dos órgãos de conservação em relação as comunidades tradicionais, engendram-se conflitos de diversas ordens, seja no plano material, seja no imaginário e simbólico. Assim questiona-se a ação do setor público que cria estas áreas, mas que, na maioria das vezes, permanecem no papel, em função de um planejamento inadequado, que desconecta a criação de áreas protegidas e a integração da comunidade neste processo. Tal contexto não é algo isolado da Amazônia, vem se efetivando no mundo todo, bem como no restante do Brasil, sendo evidenciado com mais intensidade em áreas litorâneas. Estudos como os de Simonian (1998), Santos (2008), Souza (2010) e Figueiredo, Furtado e Castro (2009) vêm analisando tal ocorrência e alertando para as possíveis modificações que possam ser engendradas nestas áreas, a partir de um modelo alienado e exógeno da práxis turística.

A APA de Algodoal/Maiandeua foi a primeira UC litorânea estadual do Pará criada pela lei $\mathrm{n}^{\circ}$ 462 de novembro de 1990, teve sua criação pautada por um processo de alienação da participação efetiva dos moradores locais (Quaresma, 2003). A mesma situa-se na porção norte do município de Maracanã, nordeste do Pará, conhecida também como Zona do Salgado. Tem como limites a baia de Marapanim, a baia de Maracanã, o Oceano Atlântico e o Canal de Mocooca que separa a ilha do continente, conforme pode-se observar na figura 1. 
Figura 1: APA de Algodoal/Maiandeua

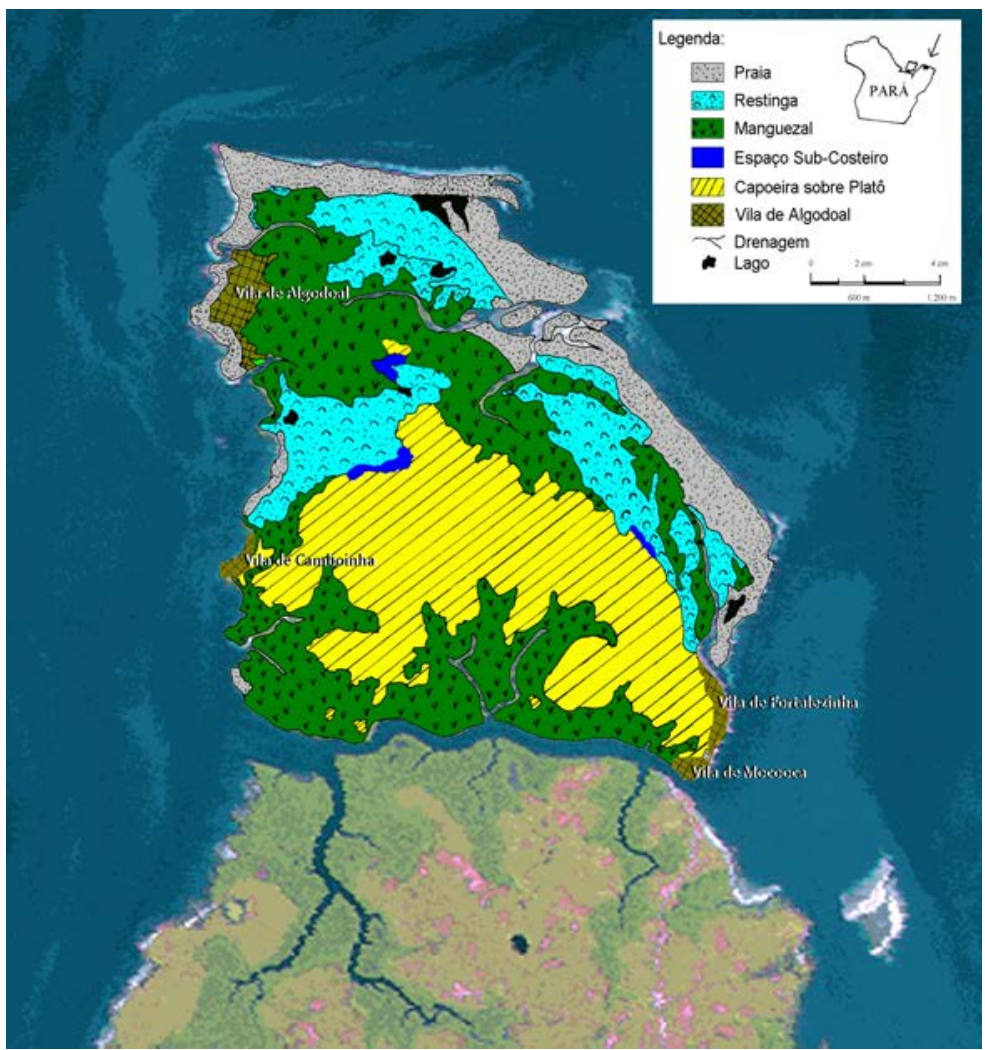

Elaboração: Altenir Pereira Sarmento - MPEG/DEL, Projeto FUNTEC (2000).

Distante do continente, o deslocamento é feito via terrestre e fluvial, tanto pelo distrito de Marudá, município de Marapanim, quanto pelo município de Maracanã, a qual está subordinada administrativamente. Composta por quatro vilas (Algodoal, Mocooca, Camboinha e Fortalezinha), sua população é formada, basicamente, por pescadores que dependem do fluxo e refluxo das marés para a prática de sua principal fonte de subsistência a pesca. Os recursos naturais (áreas de vegetação secundária - capoeira) favorecem o desenvolvimento de pequenas roças no interior da ilha onde é cultivada principalmente a mandioca, para o fabrico da farinha. Pesca e agricultura favoreceram a constituição, permanência e crescimento de uma população que desenvolveu um modo de vida integrado as disponibilidades dos recursos naturais.

A pesca, nesta área é tradicionalmente artesanal, de acordo com as necessidades de seus moradores e as especificidades ambientais. Como complemento alimentar utilizam-se de caranguejos, siris, sernambis, mexilhão e turu. Parte da produção pesqueira é colocada no mercado, através de marreteiros do próprio local ou de áreas próximas, sendo os produtos vendidos gelados e/ou salgados (secos). O turismo vem sendo a segunda atividade mais importante na ilha e desenvolve-se de maneira diferenciada pelas quatro comunidades, sendo a vila de Algodoal a que tem o processo de turistificação mais consolidado e um fluxo turístico sazonal mais intenso.

A maneira como se desenvolve o turismo na APA de Algodoal/Maiandeua vem de encontro aos objetivos de uma UC, mesmo as de uso sustentável. Os próprios moradores locais já se preocupam com esta tendência e tentam se organizar em busca de soluções imediatas para os problemas que estão a enfrentar como a deterioração ambiental, a especulação imobiliária, o turismo desordenado, lixo, desestruturação econômica, prostituição e violência, principalmente em períodos de alta temporada. Algumas ONG como 
Grupo Ambiental de Fortalezinha (GAF), SUATÁ e Associação Comunitária de Desenvolvimento da ilha de Maiandeua (ASCEDESPIN), já atuam no sentido de colaborar com o processo de minimização dos impactos ambientais tentando esclarecer a população local e os visitantes das particularidades daquele espaço, que mesmo tendo recentemente seu Conselho Gestor formado, ainda se encontra distante da prática de ações pautadas na sustentabilidade.

O plano de manejo da APAAlgodoal/Maiandeua foi concluído somente em agosto de 2012, portanto, vinte e dois anos após sua criação. O referido plano menciona que na APAAlgodoal/Maiandeua há prática do turismo rural e do ecoturismo (Pará, 2012). O plano de manejo menciona também que comunidade local realiza atividades turísticas, tais como: "caminhadas pelas praias com maré baixa com duração de mais ou menos três horas; trilhas; passeios de barco pelo litoral; observação de pássaros, dentre outras" (Pará, 2012:186). Contudo, o que existe na APA é um turismo massificado, e mal planejado principalmente na Vila Algodoal, onde as atividades e a infraestrutura presentes não são pautadas na perspectiva da sustentabilidade e muitas delas se chocam com tais princípios.

No entanto, a agricultura, a criação de animais e o turismo já estão presentes na área. Em função de sua localização, a comunidade do Quarenta do Mocooca (localizada na RESEX Marinha Maracanã) se constitui em um corredor de acesso às comunidades/praias de Fortalezinha e Algodoal (APA de Algodoal/Maiandeua), logo a renda advinda da atividade turística, está relacionada a travessia fluvial de passageiros para estas localidades, não se constituindo de fato em uma atividade efetivamente impactante na área, diferentemente da APA de Algodoal/Maiandeua.

ARESEX Marinha Maracanã, também se localiza no município de Maracanã, foi criada pelo Decreto S/N de 13 de fevereiro de 2002 e é administrada pelo ICMBIO. Abriga em sua área setenta e cinco comunidades que tem como base de sua reprodução social a pesca em uma área de 30.000 hectares (Figura 2).

Figura 2: RESEX de Maracanã

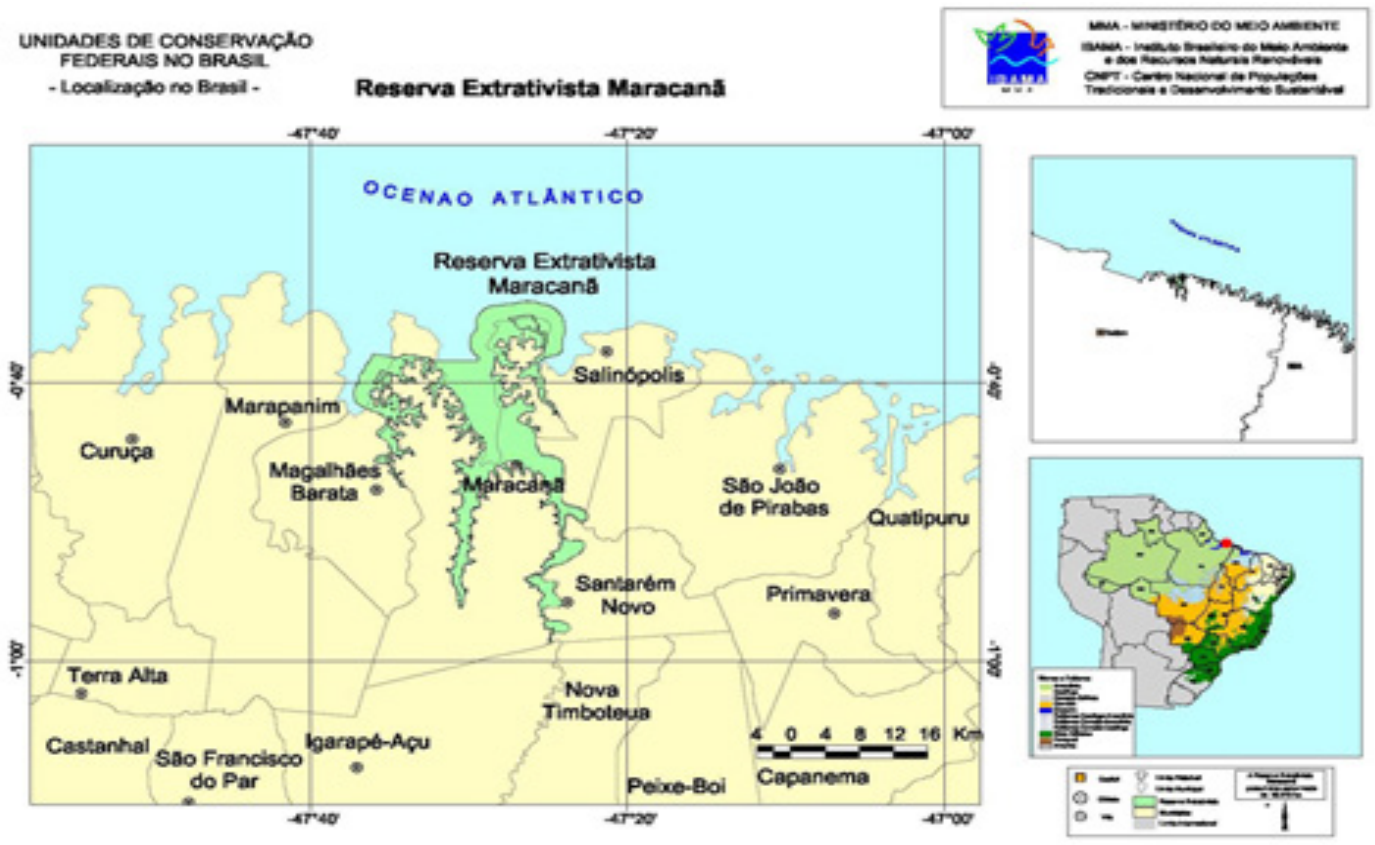

Fonte: MMA/IBAMA/CNPT

Santos (2007) analisou de que modo a RESEX contribuiu para a melhoria da qualidade do ambiente e da população local, a partir de três comunidades. Banhados pelos rios Marapanim, Cuinarana, Maracanã, 
Caripi e Baia de Maracanã, habitam na área cerca de 1.500 famílias, perfazendo aproximadamente 5.000 usuários. A vegetação abrange desde terra firme até florestas secundárias, várzea e manguezal.

Em função de um modelo de gestão específico para esta categoria de UC, já estão instituídas a Associação de Usuários da RESEX Maracanã (AUREMAR), além do Conselho Deliberativo e a Comissão de Proteção da Reserva com participação dos representantes locais responsáveis pela execução e implementação do Plano de Uso da Reserva. Em virtude da legislação específica que rege esta categoria de UC e a parceria estabelecida com outros setores da sociedade permitiram aos usuários o acesso a linhas de crédito que permitem melhorar as condições de acesso à subsistência e de qualidade de vida da população local.

A Reserva Extrativista Marinha de Caeté-Taperaçu está localizada no município de Bragança na mesorregião do nordeste paraense, foi criada pelo decreto $\mathrm{S} / \mathrm{N}$ de 20 de maio de 2005, abrangendo uma área de 42.068.086 hectares (ver figura 3) (Brasil, 2005), o que representa cerca de 20\% da área total do município (Brasil, 2012). No seu interior estão presentes três comunidades que são a Vila dos Pescadores, Vila do Bonifácio e Castelo, sendo que no seu entorno existem 55 comunidades, que foram divididas em oito polos para facilitar a sua gestão (Freitas, 2013). Segundo Brasil (2012), são cerca de 5.000 usuários seus beneficiários, sendo representados pela Associação dos Usuários da Reserva Extrativista Marinha de Caeté-Taperaçu (ASSUREMACATA).

\section{Figura 3: Mapa da Resex Caeté-Taperaçu}

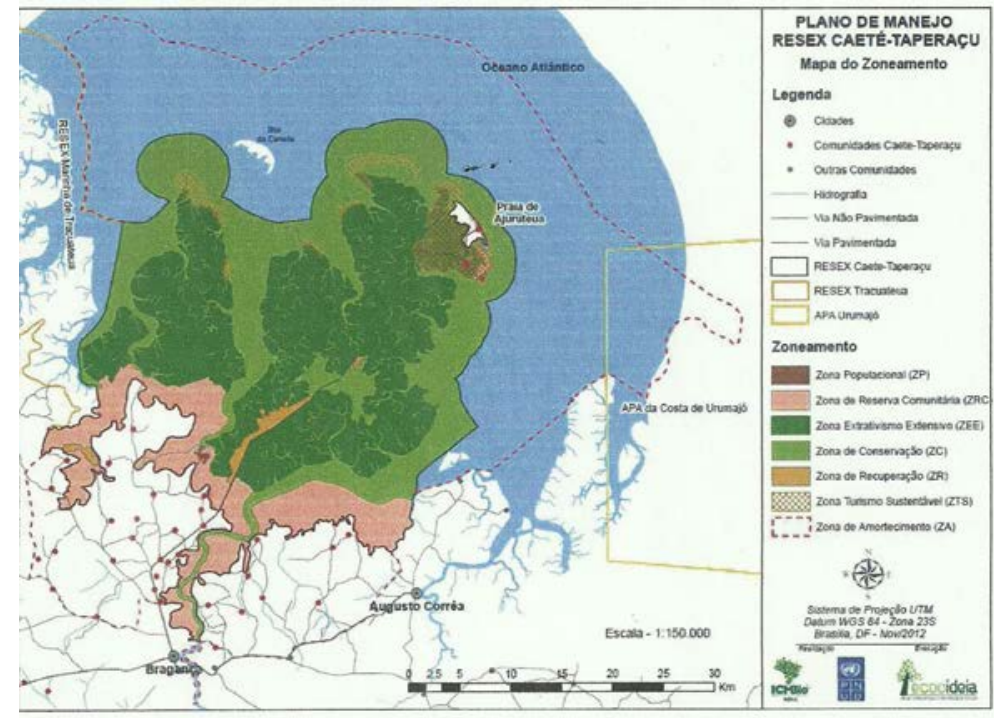

Fonte: ICMBIO, 2012

Dentre as atividades produtivas da RESEX estão, a pesca artesanal, captura de caranguejo, olarias de pequeno porte (no entorno da RESEX), artesanato de barro e agricultura familiar (Freitas, 2013). A atividade turística teve inicio na região em 1983 com a conclusão da estrada que liga a sede do município de Bragança à praia de Ajuruteua (Freitas, 2013). Ao longo dos anos, a falta de planejamento turístico levou ao uso desordenado da ocupação do solo que tornou a orla da praia com aspecto de favelização em função do turismo de massa que acontece no local.

Apesar de a praia de Ajuruteua está no polígono de exclusão da RESEX, ela está situada próximo as vilas do Bonifácio, dos Pescadores, que são comunidades inseridas no interior da RESEX. Portanto, são afetadas pelo turismo desordenado que ocorre em Ajuruteua. Uma das consequências disso, constatou-se em pesquisa de campo na vila do Bonifácio a existência de residências de veranistas, quando deveria existir somente moradia dos pescadores e catadores de caranguejo. Tal situação não poderia ocorrer, 
pois contraria os objetivos de criação das RESEX. Pois, a Zona de Turismo Sustentável, da qual as comunidades das Vilas dos Pescadores e Bonifácio fazem parte, permite instalações ecoturísticas de baixo impacto, desde que autorizadas pelo Conselho Deliberativo (Brasil, 2012).

Freitas (2013) menciona que está sendo realizada uma parceria entre o setor público estadual e municipal para o desenvolvimento de projetos de turismo rural. Porém, segunda a autora, este não está envolvendo as comunidades que serão afetadas pelo mesmo, ou seja, a comunidade está excluída da participação. Tal situação contradiz com o processo de criação e participação das comunidades nas decisões da UC, principalmente as de uso sustentável. Conforme afirma Freitas (2013:97), a comunidade pode se tornar apenas um expectador. Ainda para autora, o fluxo turístico fica restrito a praia de Ajuruteua, não beneficiando a RESEX como atrativo ambiental e sociocultural. No entanto, o que os moradores da RESEX querem é desenvolver o turismo sustentável de base comunitária diferente do que acontece na praia de Ajuruteua. Embora o plano de manejo contemple no seu subprograma de desenvolvimento do turismo a criação do turismo de base comunitária, o que se percebe na atualidade na chamada Zona de Turismo Sustentável é um turismo sem planejamento e desordenado reflexo do turismo massificado da praia de Ajuruteua.

A Reserva Extrativista Marinha Mãe Grande de Curuça, foi criada pelo Decreto S/N de 13 de dezembro de 2002, e esta sob a gerência do ICMBIO. Com uma área de 37.062 hectares (Figura 4), integra a maior zona de manguezais do planeta, que vai desde o Pará até o Maranhão. Abrange 52 comunidades de pescadores artesanais, um distrito (São José do Abade) e o núcleo urbano do município de Curuça, perfazendo um total de 3.000 famílias (Souza, 2010).

Figura 4: RESEX Mãe Grande de Curuça

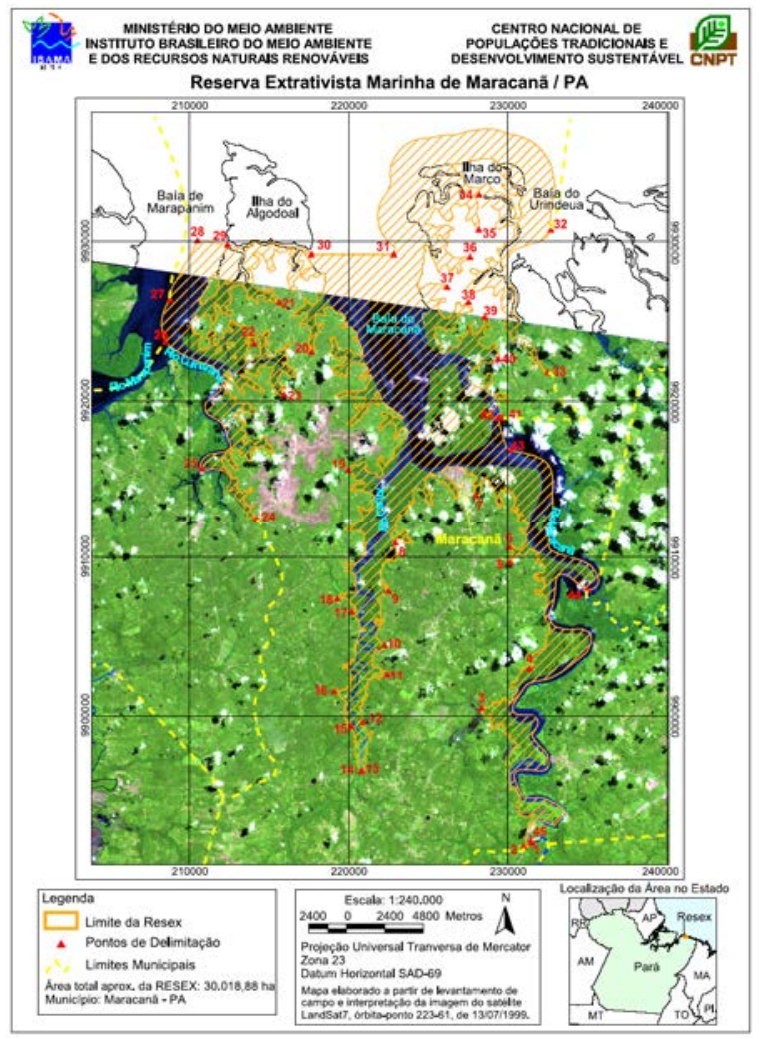

Fonte: IBAMA, 2011. 
A existência de diferentes graus de desenvolvimento na localidade faz com que haja níveis diferenciados de problemas na região, evidenciando a complexidade que envolve essa UC. AAssociação dos Usuários da Reserva Extrativista Mãe Grande de Curuçá (AUREMAG) atua na área a partir de um conselho deliberativo que integra representantes de várias instituições. A estratégia de gestão adotada na RESEX foi a instalação de pólos com comitês comunitários em Caratateua, Ramos, Candeua, Cutumateua, Boa Vista, Nazaré de Mocajuba e a sede do município. No entanto, é possível identificar o pouco conhecimento/ informação que as comunidades mais distantes têm desta RESEX.

O turismo na RESEX já é uma presença efetiva. A diversidade ecossistêmica e cultural permite ao visitante ter acesso a um vasto patrimônio sócioambiental. O Instituto Peabiru em conjunto com a Estação Guabiraba5 desde 2006 vinham "dando apoio na divulgação e venda de roteiros turísticos" (Instituto, 2011:2). A experiência do Grupo Tapiaim de Ecoturismo6, dinamizado e gerido pelas instituições acima citadas, se apresentou no sentido inverso ao da massificação turística, se propondo a desenvolver o turismo de base comunitária e a perspectiva de um contato mais efetivo com a comunidade. No entanto, em função de dinâmicas pessoais o grupo se dissolveu e as ações de turismo dinamizadas pelo grupo sofreram descontinuidades (Queiroz, 2011).

Há ações realizadas pelo poder público para o desenvolvimento do turismo. A Secretaria Municipal de Turismo de Curuçá criou o "Roteiro do Sol" que oportuniza aos visitantes e turistas conhecer as ilhas e as praias de RESEX Mãe Grande (Falcão, 2013). Empreendimentos privados também estão sendo realizados para o turismo na RESEX. Em 2011, foi construído um bar-pousada na praia da ilha da Romana com o objetivo de acolher melhor os visitantes que atravessam para essa ilha, que é a mais visitada da RESEX, pois tem um ecossistema conservado e é semidesabitada (Falcão, 2013). No entanto, o trabalho de Figueiredo, Furtado e Castro (2009:1) evidencia zonas de conflitos no interior da RESEX, principalmente nas comunidades mais próximas aos serviços/acesso urbano, no caso São João do Abade:

Os problemas identificados estão ligados principalmente aos recursos aquáticos, locais e os mais recorrentes são: disputas por pontos de pesca, roubos de embarcações, prática constante de técnicas predatórias de pesca e coleta, degradação e ocupação desordenada de áreas de manguezais, prostituição e aumento considerável nos últimos anos do consumo de álcool e drogas no meio pesqueiro.

Muitos destes problemas se configuram pela presença de atividades exógenas impactantes como a pesca industrial e a perspectiva da construção de um grande porto de escoamento minero-graneleiro do estado.

\section{Considerações Finais}

O desafio em buscar compreender as questões relativas a problemática do turismo em áreas protegidas na Amazônia foi o elemento impulsionador deste estudo, pois acredita-se que tal atividade pode contribuir sobremaneira para a consolidação das áreas protegidas, associada a prática de um turismo sustentável e promotor de um desenvolvimento coletivo e integrado. Os trabalhos de Rodrigues (1999), Swarbrooke (2000), Giraldella e Neiman (2010) e Neiman e Patrício (2010) demonstram a viabilidade do turismo sustentável enquanto atividade que conjuga aspectos sociais, ambientais e econômicos buscando a maximização dos impactos positivos e minimização dos negativos, e tê-lo como instrumento de desenvolvimento, se constitui em um passo para o compartilhamento de responsabilidades. Estudos isolados nesta área, como os de Pinto e Campos (1994), Endres (1996), Cruz (1999), Pinto (2000), Campos (2008), e Quaresma (2000, 2008), Pessoa e Rabinovici (2010) reforçam a necessidade do preenchimento das lacunas existentes acerca de tal temática. O tema em questão é de fundamental importância para se tentar compreender os entraves que gravitam em torno das UC e a prática do turismo, principalmente quando este é direcionado a áreas haliêuticas, onde toda a estrutura de relações socioambientais é estabelecida a partir de uma interação harmônica com o ambiente.

Buscar alternativas para a efetivação destas áreas e seus planos de manejo através do turismo, constitui-se em um dos caminhos para o êxito das mesmas. O mesmo pode ser dito quanto ao desenvolvimento de um turismo regional pautado por políticas públicas comprometidas com todos os setores envolvidos no processo, principalmente as populações locais, associado com a sustentabilidade dos recursos naturais. Seria importante, talvez, adotar uma visão sistêmica do processo em questão, em busca de um planejamento o mais racional possível do turismo. 
A questão a ser repensada é o fato de o turismo ser apresentado a estas comunidades como a "grande saída" econômica para o desenvolvimento das sociedades haliêuticas. No entanto, os agentes responsáveis por disseminar esta visão a percebem a partir de um prisma imediatista, em curto prazo, meramente economicista, reforçando a perspectiva da "monocultura" da atividade. Há necessidade de se perceber o turismo como uma atividade transversal, complexa e a partir da qual desdobramentos outros poderão ser efetivados, dependendo da condução que venha a ser dado a mesma e do verdadeiro papel desenvolvido pelos agentes envolvidos na atividade.

Neste caso, atores diferenciados (Estado, empresários e sociedade civil) teriam condições de se articular com um objetivo comum, a implantação do turismo como alternativa de desenvolvimento eficaz e benéfico, principalmente para as comunidades residentes nas áreas utilizadas para este fim. Somente através desta participação comum, do conhecimento do como, quando, porque e para quem é que será possível o desenvolvimento de um turismo coerente, norteado por critérios estabelecidos pelos agentes envolvidos neste processo. Garantir-se-á, desse modo, não só o aproveitamento racional dos recursos como a não exclusão de comunidades locais no processo de conduzir sua própria história.

É necessário que seja revista a maneira de planejamento e gestão das UC, a fim de que possam alcançar seus objetivos. No dizer de Kinker (2002:9), isto já vem se efetivando como uma nova ordem mundial, pois essas unidades não sobreviverão se não se integrarem de fato a um planejamento regional, fornecendo oportunidades de desenvolvimento local e de seu entorno. E para Yazigi (1999:70) é fundamental que isso se processe a partir da ideia de "auto-sustentação" das UC, em favor da preservação de maneira singularizada.

Isso é referendado a partir das realidades expostas neste trabalho no qual se contextualiza experiências de UC, duas categorias distintas de gestão e organização social (APA e RESEX), mas que tem em comum um cenário semelhante no que diz respeito a participação e uso destes recursos, inclusive pela atividade do turismo. Souza (2010:93) consegue descrever muito bem este cenário que se aplica a várias categorias de UC ao mencionar que:

Nas Resex marinhas a exclusão dos não comunitários e a falta de gerenciamento de áreas de exploração de outros recursos naturais podem levar a conflitos nas áreas do entorno, ao enfraquecimento na manutenção das atividades destas populações e a exclusão por setores economicamente mais fortes como a pesca industrial, o turismo e a especulação imobiliária.

É válido afirmar que a dimensão continental do Brasil se coloca como um dos elementos que dificultam o êxito das UC, associado as carências financeiras e de recursos humanos. Na Amazônia, estes problemas se configuram de modo ainda mais intenso, em função não só da própria dimensão da região, como também das distâncias internas que dificultam as ações na região. Em decorrência destes quadros, uma série de outras situações se constrói oriundas, não só das próprias ações mesológicas, como também de ações antrópicas imputadas à região, entre elas o turismo. No entanto, há que se recuperar os atrasos oriundos de condutas equivocadas, de fragilidades legislativas, fiscais e financeiras, superar os interesses políticos em prol de um compromisso real com ambiente natural e com as populações humanas que dependem destes ecossistemas existentes na região. Acredita-se que as UC e o turismo se constituem em alternativas viáveis de sustentabilidade para a região amazônica.

\section{Bibliografia}

Adrião, Denize Genuína da Silva

2003. Um olhar acerca da mudança nas relações de trabalho e na organização social entre as famílias dos pescadores diante do turismo balnear em Salinópolis. Tese (Doutorado em Ciências Sociais) Departamento de Sociologia do Instituto de Filosofia e Ciências Humanas, Universidade Estadual de Campinas. Campinas.

Brasil

2000. Lei $\mathrm{n}^{0} 9.985$ de 18 de Julho de 2000. Institui o Sistema Nacional de Unidades de Conservação (SNUC). Disponível em <http:// www.mma.gov.br >. Acesso em: 18 jun. de 2013. 
Brasil

2012. Plano de Manejo da Reserva Extrativista Marinha de Caeté-Taperaçu - Volume I: Diagnóstico. Instituto Chico Mendes de Conservação da Biodiversidade, Brasília.

Brasil

2012. Plano de Manejo da Reserva Extrativista Marinha de Caeté-taperaçu - Volume II: Planejamento.

Instituto Chico Mendes de Conservação da Biodiversidade, Brasília, 2012.

Campos, Raul Ivan Raiol de

2008. Sustentabilidade, turismo e gestão do patrimônio arqueológico: limites e possibilidades no Maracá

(AP) e Serra dos Martírios/Andorinhas (PA). Tese (Doutorado em Desenvolvimento Sustentável do

Trópico Úmido) - Universidade Federal do Pará. Belém.

Castro, Celso Antônio Pinheiro de

2002. Sociologia aplicada ao turismo. São Paulo, Atlas

Costa, Patrícia Côrtes

2002. Unidades de conservação, matéria-prima do ecoturismo. São Paulo: Aleph.

Costa, Vibian Carvalho; Costa Nadja Maria C. da.

2000. "O Desafio do ecoturismo em unidades de conservação." In: Encontro Nacional de Turismo com

Base Local IV. Joenvile, Instituto Superior e Centro Educacional Luterano Bom Jesus/IELUSC, 15 a

18/11/2000. Disponível em <http://www.redebonja.cbj.g12.br/ielusc/turismo>. Acessado em: 14 set. 2003.

Cruz, Silvia Helena Ribeiro.

1999. "Turismo: a percepção dos residentes da vila do Pesqueiro, Município de Soure, Ilha do Marajó/ Pa”. In: Figueireo, Sílvio Lima (org.). O Ecoturismo e a questão ambiental na Amazônia. Belém: UFPa./NAEA.

De Masi, Domenico

2001. "Turismo e tempo livre: uma alternativa para o terceiro milênio". In: Faria, Ivani Ferreira de (org.).

Turismo: lazer e políticas de desenvolvimento local. Manaus: Editora da Universidade do Amazonas.

Diegues, Antônio Carlos S. A.

1994. O Mito moderno da natureza intocada. São Paulo: NUPAUB/USP.

D`incao, Maria Ângela.

1994. "Limites culturais na responsabilidade da biodiversidade". In: Silveira, Isolda Maciel da; D`incao, Maria Ângela (Org.). A Amazônia e a crise da modernização. Belém: Museu Paraense Emílio Goeldi. Endres, Ana Valéria

1996. Ecoturismo na área de Proteção Ambiental de Algodoal/Maiandeua. Belém, UFPa./NAEA, (Monografia de Especialização).

Falcão, Laércio Bezerra

2013. Turismo em Resex: perspectivas de desenvolvimento, participação social e políticas públicas nas Resex de Soure e Curuça no Pará. Dissertação (Mestrado Profissional em Turismo). Programa de

Pós-Graduação em Turismo, Centro de Excelência em Turismo da Universidade de Brasília. Brasília. Fennel, David

2002. Ecoturismo uma introdução. São Paulo: Contexto.

Figueiredo, Elida Moura; Furtado, Lourdes Gonçalves e Castro, Edna Ramos.

2009. "Trabalhadores da pesca e a Reserva Extrativista Marinha Mãe Grande de Curuça-Pa: impactos socioambientais da rodovia PA-136”. In: Amazônia: Ci \& Desenv. v. 5, n. 9.

França, Dalva Lúcia de Souza

2008. Turismo e dinâmica demográfica: reflexos da atividade turística no comportamento reprodutivo da mulher no Município de Salinópolis, PA. Dissertação (Mestrado em Geografia) - Programa de Pós-Graduação em Geografia, Universidade Federal do Pará. Belém

Freitas, Letícia Lima de

2013. Sustentabilidade Sociocultural e Turismo na Reserva Extrativista Marinha de Caeté-Taperaçu. Dissertação (Mestrado Profissional em Turismo). Programa de Pós-Graduação em Turismo, Centro de Excelência em Turismo da Universidade de Brasília. Brasília.

Furtado, Lurdes G

1987. Curralistas e rendeiros de Marudá: pescadores do litoral do Para. Belém: Museu Paraense Emílio Goeldi

Furtado, Lurdes G.

1994. "Comunidades tradicionais: sobrevivência e preservação ambiental”. In: Silveira, Isolda Maciel da; D`incao, Maria Ângela (Org.). A Amazônia e a crise da modernização. Belém: Museu Paraense Emílio Goeldi.

Giraldella, Heloana; Neiman, Zysman

2010. "Planejamento e gestão em áreas naturais protegidas". In: Neiman, Zysman; Rabinovici, Andrea. (Orgs.). Turismo e meio ambiente no Brasil. Barueri: Manole. 
Gomes, Eduardo Lima dos Santos

2007. Turismo no entorno do Parque Nacional do Cabo Orange, Amapá. Dissertação (Mestrado em Planejamento do Desenvolvimento). Programa de Pós-Graduação em Desenvolvimento Sustentável do Trópico Úmido da Universidade Federal do Pará, Núcleo de Altos Estudos Amazônicos. Belém.

Hebete, Jean

1985. "Grandes projetos e transformações na fronteira". Revista Espaço e Debates. v.5, n.15: 75-85.

Ignarra, Luiz Renato

1999. Fundamentos do turismo. São Paulo: Pioneira.

Instituto Tapiain. Disponível em: <http://institutotapiaim.blogspot.com/>. Acesso em: 12. mai. 2011.

Irving, Marta de Azevedo

2002. "Refletindo sobre ecoturismo em áreas protegidas - tendências no contexto brasileiro". In: IRVING,

Marta de Azevedo; AZEVEDO Júlia (orgs.). Turismo - desafio da sustentabilidade. São Paulo: Futura

Irving, Marta de Azevedo; Rodrigues, Camila G.de Oliveira e Neves Filho, Nilton de Castro.

2002. "Construindo um modelo de planejamento turístico de base comunitária - um estudo de caso".

In: Irving, Marta de Azevedo; Azevedo, Júlia (Org.). Turismo - desafio da sustentabilidade. São Paulo: Futura.

Kinker, Sônia

2002. Ecoturismo e conservação da natureza em Parques Nacionais. Campinas: Papirus (Coleção Turismo).

Krippendorf, Jost

1989. Sociologia do turismo: para uma nova compreensão do lazer e das viagens. Rio de Janeiro: Civilização Brasileira.

Lemos, Amália Inês G de

1996. Turismo: impactos sócio ambientais. São Paulo: Hucitec.

Lima, Deborah; Pozzobon, Jorge

2005. "Amazônia socioambiental, sustentabilidade ecológica e diversidade". In: Estudos Avançados, v. 19 (54): 45-76.

Maneschy, Maria Cristina

1993. Ajuruteua, uma comunidade pesqueira ameaçada. Belém: UFPA/CFCH.

Mcneely, J. A.

1984. "Introduction: protected areas adapting to new realities". In: Mcneely, J. A; Miller, K.R (Org.). National Parks, Conservation and Development. Washington, D,C: Smithsonian Institute Press.

Medeiros, Rodrigo; Young, Carlos Eduardo Frickmann

2011. Contribuição das unidades de conservação brasileiras para a economia nacional: relatório final. Brasília: UNEP-WCMC.

Moreira, Adriana, Anderson, Antony

1996. "Unidades de Conservação no Brasil: populações tradicionais, Estado e sociedade". In: Presença humana em unidades de conservação - Anais do Seminário Internacional sobre Presença Humana em Unidades de conservação. Brasília.

Naisbitt, J.

1994. Paradoxo global. Rio de Janeiro: Campus.

Nascimento, Vânia Lúcia Quadros

2009. Políticas públicas de turismo e participação: a trajetória do PROECOTUR no pólo Belém/Costa Atlântica. Dissertação (Mestrado em Planejamento do Desenvolvimento) - Núcleo de Altos Estudos Amazônicos, Universidade Federal do Pará. Belém.

Neiman, Zysman e Patricio, Raquel Formaggio

2010. "Ecoturismo e conservação dosa recursos naturais". In: Neiman, Zysman; Rabinovici , Andrea. (Org.). Turismo e meio ambiente no Brasil. Barueri: Manole, 2010. p. 84-104.

Nieffer, Inge Andréa, Silva , João Carlos G. L. da, e Amend, Marcos

2000. "Ecoturistas ou não? Análise preliminar dos visitantes do parque Nacional de Superagui". Turismo - visão e ação, Ano 3, n. 6: 49-68.

Pará

2009. Secretaria de Estado de Meio Ambiente. Belém: SEMA.

Pará

2012. Secretaria de Estado de Meio Ambiente. Plano de Manejo da Área de Proteção Ambiental de Algodoal-Maiandeua. Belém: SEMA.

Pereira, Polyana Faria; Scardua, Fernando Paiva

2008. "Espaços territoriais especialmente protegidos: conceito e implicações jurídicas". Ambiente \& Sociedade, v. XI, n. 1: 81-97.

Pessoa, Mara Aristeu; Rabinovici, Andréa

2010. "Inserção comunitária e as atividades do turismo". In: Neiman, Zysman; Rabinovici, Andrea. (Orgs.). Turismo e meio ambiente no Brasil. Barueri: Manole. 
Pinto, Paulo Moreira. Campos, Raul Ivan Raiol de

1994. Turismo ecológico: uma proposta de desenvolvimento sustentável para a área de proteção Ambiental de Belém. Belém: NUMA/UFPA.

Pinto, Paulo Moreira

2000. "Unidades de Conservação da Amazônia: o ecoturismo no Parque Estadual da Serra dos Martírios/ Andorinhas". In: Coelho, Maria Célia Nunes. Simonian, Lígia T. L., Fenzel, Norbert. (Org.). Estado e políticas públicas na Amazônia. Belém: CEJUP.

Pinto, Paulo Moreira

2006. Unidades de conservação, turismo e exclusão social no Parque Estadual da Serra dos Martírios/ Andorinhas. Dissertação (Mestrado em Serviço Social) - Universidade Federal do Pará. Belém.

Quaresma, Helena Doris de A. Barbosa.

2003. O Desencanto da princesa: pescadores tradicionais e turismo na Área de Proteção Ambiental de Algodoal/Maiandeua. Belém: NAEA/UFPA.

Quaresma, Helena Doris de A. Barbosa

2008. Turismo na Terra de Makunaima: sustentabilidade em parques nacionais da Amazônia. Tese (Doutorado em Desenvolvimento Sustentável do Trópico Úmido) - Universidade Federal do Pará, Belém.

Queiroz, Jacirene da Silva

2011. Ecoturismo de base comunitária na Amazônia Oriental: o caso do Instituto Tapiaim em Curuçá PA. Dissertação (Mestrado em Agricultura Familiar e Desenvolvimento Sustentável) - Universidade Federal do Pará. Belém.

Rodrigues, Adyr, A . B.

1996. Turismo e Geografia: reflexões teóricas e enfoques regionais. São Paulo: HUCITEC.

Rodrigues, Adyr, A. B.

1999. "Turismo local: oportunidades para inserção". In: Rodrigues, Adyr Balestreri (org.). Turismo $e$ desenvolvimento local. São Paulo: Hucitec.

Ruschmann, Doris

1997. Turismo e planejamento sustentável: a proteção do meio ambiente. São Paulo. HUCITEC, 1997.

Sansolo, Davis Gruber

2002. "Turismo - aproveitamento da biodiversidade para a sustentabilidade". In: Irving, Marta d Azevedo; Azevedo, Júlia (orgs.). Turismo - o desafio da sustentabilidade. São Paulo: Futura.

Santos, Jeyza Lobato

2008. "Reserva Extrativista como Alternativa para a Sustentabilidade Local: O Caso da Resex Marinha Maracanã - Pará”. In: IV Encontro da Associação Nacional de Pós-graduação e Pesquisa em Ambiente e Sociedade (ANPPAS).

Seabra, Giovanni

2001. Ecos do turismo - o turismo ecológico em áreas protegidas. Campinas. Papirus.

Simonian, Ligia. T. L.

1996."Hidrelétrica de Samuel (RO) e populações tradicionais: deslocamento compulsório e outras questões". In: Magalhães, Sônia et al (Org.). Energia na Amazônia. Belém: Museu Paraense Emílio Goeldi.

Simonian, Ligia. T. L.

1998. Parques Nacionais e Indígenas na Amazônia Ocidental: imposições, destruição e resistência. Belém, Working Paper.

Simonian, Ligia. T. L.

2000. "Políticas públicas, desenvolvimento sustentável e recursos naturais em áreas de reserva na Amazônia". In: Coelho, Maria Célia N; Simonian, Ligia T. L.; Fenzel, N. (Org). Estado e políticas públicas na Amazônia. Belém: CEJUP.

Simonian, Ligia. T. L.

2003. Ilha de muitos recursos, histórias e habitantes: a experiência de Trambioca, Barcarena PA. Belém: NAEA/UFPA; CNPT-PA/IBAMA.

Souza, Charles Benedito Gemaque

2010. "A gestão dos recursos naturais na Amazônia: a Reserva Extrativista Mãe Grande de Curuça-Pa". In: Revista Geografar, v. 5 n. 1: 83-104.

Stronza, Amanda

2001. "Anthopology of Tourism: forging news ground for ecotourism and other alternatives". In: Annual review of anthropology. v. 30.

Swarbrooke, John

2000. Turismo sustentável: conceitos e impactos ambiental. São Paulo: Aleph.

Veríssimo, Adalberto; Rolla, Alicia;Vedoveto, Mariana; Futada, Silvia de Melo. (Org.)

2011. Áreas Protegidas na Amazônia brasileira : avanços e desafios. Belém : Imazon ; São Paulo : Instituto Socioambiental.

World Wildlife Fund-Brasil

2011. Efectividade de gestão das Unidades de Conservação do estado do Pará. Brasília: WWF-Brasil. 
Yázigi, Eduardo

1999 .Turismo uma esperança condicional. São Paulo: Global.

\section{NOTAS}

1 Estados que compõem: Pará, Maranhão, Amapá, Tocantins e Mato Grosso.

2 Segundo De Masi (2001:10), "neste tipo, os turistas querem ver em pouco tempo o maior número de coisas [...] gostam de fastfood, coca-cola e de lugares com muita gente. [...] têm uma atitude devastadora. Esperam pouco e oferecem pouco".

3 “[...] os novos vândalos são os seres do nosso cotidiano, os eleitos das três esferas de governo, os administradores privados, nossos familiares, amigos, vizinhos e correligionários..., e quem sabe nós mesmos" (Yázigi, 1999:78).

4 "Entende-se a capacidade de uma dada população de ocupar uma determinada área e explorar seus recursos naturais sem ameaçar, ao longo do tempo, a integridade ecológica do meio ambiente" (Lima; Pozzobon, 2005: 45).

5 Operadora de Turismo.

6 Entidade - formada por filhos de pescadores, agricultores e professores de Curuçá - que visa a partir do Ecoturismo de Base Comunitária, resgatar e valorizar a cultura, a história e a conservação do meio ambiente (Instituto, 2011). 